\title{
Nutrient co-limitation at the boundary of an oceanic gyre
}

Thomas J. Browning ${ }^{1}$, Eric P. Achterberg ${ }^{1}$, Insa Rapp ${ }^{1}$, Anja Engel ${ }^{1}$, Erin M. Bertrand $^{2}$, Alessandro Tagliabue ${ }^{3}$, C. Mark Moore ${ }^{4}$

${ }^{1}$ Marine Biogeochemistry Division, GEOMAR Helmholtz Centre for Ocean Research, Kiel 24148, Germany.

${ }^{2}$ Department of Biology, Dalhousie University, Halifax B3H 4R2, Canada.

${ }^{3}$ Department of Earth, Ocean and Ecological Sciences, School of Environmental Sciences, University of Liverpool, Liverpool L69 3GP, UK.

${ }^{4}$ Ocean and Earth Science, National Oceanography Centre Southampton, University of Southampton, Southampton SO14 3ZH, UK.

*Correspondence to: tbrowning@geomar.de

Nutrient limitation of oceanic primary production exerts a fundamental control on marine food webs and the flux of carbon into the deep ocean ${ }^{1}$. The extensive boundaries of the oligotrophic sub-tropical gyres collectively define the most extreme transition in ocean productivity, but little is known about nutrient limitation in these zones ${ }^{1-4}$. We conducted full factorial nutrient amendment experiments in the eastern boundary of the South Atlantic gyre and found extensive regions where supplying nitrogen or iron individually resulted in no significant phytoplankton growth over 48 hours, but adding both increased chlorophyll-a concentrations by up to $\sim 40$-fold, led to diatom proliferation, and reduced community diversity. Once nitrogen-iron co-limitation had been alleviated, addition of cobalt or cobalt-containing vitamin $B_{12}$ could further enhance chlorophyll-a yields up to 3-fold. Our results imply nitrogen-iron colimitation is pervasive in the ocean, with other micronutrients also approaching co-deficiency. Such multi-nutrient limitations potentially increase phytoplankton community diversity.

From the results of nutrient-enrichment experiments performed to date, oceanic phytoplankton would appear to be proximally limited by the availability of either nitrogen $(\mathrm{N})$ or iron $(\mathrm{Fe})^{1}$. Despite widespread observations of both nutrients being at low concentrations simultaneously ${ }^{2}$, relatively little direct evidence exists for colimitation of phytoplankton growth by these elements ${ }^{3,4}$. Furthermore, field evidence for (co-)limitation by micronutrients other than $\mathrm{Fe}$ is sparse ${ }^{5,6}$. Characterization and even definition of nutrient 'co-limitation' can be complex ${ }^{7-9}$ (Supplementary Discussion). However, the simplest case corresponds to two strictly essential nutrients (e.g., $\mathrm{N}$ and $\mathrm{Fe}$ ) being concurrently drawn down to levels where only the supply of both in combination results in a significant biomass growth response. Such 'simultaneous co-limitation' occupies a midpoint in resource ratio space relative to single limitation and serial (or secondary) limitation ${ }^{10,11}$, the latter representing the circumstance where a second nutrient only becomes limiting following addition of the first.

Considerations of such transitions in resource space remain largely theoretical ${ }^{8,10,12,13}$, limiting our understanding of (co-)limitation in nature. An additional factor complicating widespread predictions of oceanic (co-)limitation relates to 
reconciliation of operationally defined dissolved seawater nutrient concentrations with flexible phytoplankton demands ${ }^{1}$. When evaluated within an appropriate framework $^{1,8}$, the clearest means of demonstrating oceanic nutrient (co-)limitation patterns and the associated short-term ecophysiological responses to nutrient resupply are via direct testing in trace-metal-clean nutrient amendment bioassay experiments conducted with a factorial design. However, the logistical challenges associated with this approach have limited applications to few studies employing more than two nutrients ${ }^{1}$.

To resolve potential (co-)limitation of phytoplankton communities by the three nutrients identified as most deficient in the South Atlantic gyre ${ }^{1}$, we conducted 48 hour duration full-factorial $\mathrm{N}, \mathrm{Fe}$, and cobalt (Co) addition bioassay experiments throughout the SE Atlantic. This region receives relatively little dust input and is host to a marked productivity transition between the eastern boundary Benguela upwelling regime, a globally important fishery, and the South Atlantic oligotrophic gyre (Fig. $1)^{14}$. To elucidate the potential biochemical function of added $\mathrm{Co}$, an additional $\mathrm{N}+\mathrm{Fe}+\mathrm{Co}$-containing vitamin $\mathrm{B}_{12}$ amendment was also conducted. Experiments were carried out on the German GEOTRACES cruise GA08, in December 2015 (Fig. 1a), with surface seawater collected using a towed trace-metal-clean sampling system, and shipboard incubations performed in triplicate and interpreted relative to untreated controls and the initial biogeochemical characterization of ambient seawater. Phytoplankton responses to nutrient amendment were assessed via changes in chlorophyll-a concentrations, flow cytometry cell counts of key phytoplankton groups, concentrations of diagnostic phytoplankton pigments, and nutrient-stressspecific active chlorophyll fluorescence measurements ${ }^{15,16}$.

Away from fully nutrient replete coastal upwelling waters, bulk phytoplankton community responses demonstrated transitions between $\mathrm{N}$ and $\mathrm{Fe}$ (single/serial/co)limitations (Fig. 1 and Extended Data Fig. 1). Aside from the coastal sites (Experiments 1 and 11), chlorophyll-a increased at two sites following amendment with $\mathrm{N}$ alone (Experiments 3 and 4), three sites exhibited responses that were consistent with serial limitation by $\mathrm{N}$ and $\mathrm{Fe}$ (Experiments 2,5 and 6), and four experiments (Experiments 7-10) showed increases that were only significant following amendment with $\mathrm{N}+\mathrm{Fe}$. Together, these results imply widespread conditions at or approaching N-Fe co-limitation. At the clearly co-limited sites, accumulation of larger cells (approximately $>2 \mu \mathrm{m}$ ) only occurred following amendment with at least $\mathrm{N}+\mathrm{Fe}$ (Fig. 2a and Extended Data Fig. 2). In contrast, average cell counts of the cyanobacteria Synechococcus and Prochlorococcus typically exhibited no changes or reductions following supply of $\mathrm{N}+\mathrm{Fe}$, suggesting they were grazer-regulated and/or out competed by the larger cells ${ }^{17,18}$. However, magnitudes of cellular fluorescence, indicative of pigmentation per cell, generally increased with $\mathrm{N}$ or $\mathrm{N}+\mathrm{Fe}$ amendment for the prokaryotes, suggesting physiological recovery from initial nutrient limitation despite limited biomass accumulation (Fig. 2b and Extended Data Figs 3-5) ${ }^{17}$.

Responses to $\mathrm{N}+\mathrm{Fe}$ amendment were most pronounced at the sites with strongest $\mathrm{N}$ Fe co-limitation (Experiments 8-10). Responses to addition of $\mathrm{N}$ or Fe alone were not statistically significant at these locations, whereas chlorophyll-a biomass increased 21-38 times that of control samples in response to addition of N+Fe (Fig. 1). Although dramatic, the responses to $\mathrm{N}+\mathrm{Fe}$ amendment in three of the experiments remained modest in comparison to $\mathrm{N}+\mathrm{Fe}+\mathrm{Co}$ or $\mathrm{N}+\mathrm{Fe}+$ vitamin $\mathrm{B}_{12}\left(2 \mathrm{nmol} \mathrm{L}{ }^{-1}\right.$ added 
$\mathrm{Co} ; 100$ pmol L ${ }^{-1} \mathrm{~B}_{12}$ ), where up to an additional 2-to-3-fold increase in chlorophyll-a biomass was observed (Experiments 7-9). Importantly, enhanced chlorophyll-a resulted from higher phytoplankton abundances, rather than increased cellular pigmentation alone (Fig. 2a and Extended Data Figs 2-5). Thus, over large oceanographic extents there was a clear upper limit on potential biomass accumulation, for at least the larger-celled community (Fig. 2), upon supply of N+Fe relative to that achievable with additional supply of Co or vitamin $B_{12}$.

The delicate balance of N-Fe co-limitation was clear in responses of the communitylevel physiological indicator, $F_{\mathrm{v}} / F_{\mathrm{m}}$ (Fig. 1 and Extended Data Fig. 6) ${ }^{16}$. Experiments 6 and 8-10 were at or approaching co-limitation and had elevated initial $F_{\mathrm{v}} / F_{\mathrm{m}}$, characteristic of either nutrient replete, proximally N-limited, or N-Fe co-limited systems ${ }^{16}$. N amendment at these sites (alone or in combination with $\mathrm{Co}$, but in the absence of $\mathrm{Fe}$ ) resulted in significant $F_{\mathrm{v}} / F_{\mathrm{m}}$ reductions. Such reductions result from greater $\mathrm{Fe}$ stress ${ }^{16}$ and match responses observed at $\mathrm{N}-\mathrm{Fe}$ co-limited sites in the Equatorial Pacific ${ }^{3}$. Diurnal $F_{\mathrm{v}} / F_{\mathrm{m}}$ cycles, including marked nocturnal decreases (Extended Data Fig. 7), also generally matched those previously observed in the colimited Pacific ${ }^{3}$. Conversely, at Experiment 7 (also co-limited) low initial $F_{\mathrm{v}} / F_{\mathrm{m}}$ and increases following Fe amendment presumably represented recovery from proximal physiological Fe stress, despite N-Fe co-limitation of biomass accumulation.

Qualitative community level biomass and $F_{\mathrm{v}} / F_{\mathrm{m}}$ responses to $\mathrm{N}$ and/or Fe amendment were both predictable on the basis of observed seawater nutrient (dissolved $\mathrm{N}$ and $\mathrm{Fe}$ ) concentrations, as illustrated on resource ratio plots (Fig. 3a-c) ${ }^{10,11}$. Despite acknowledged complexity in phytoplankton responses to nutrient amendment (Supplementary Discussion), biomass accumulation could also be quantitatively reproduced using a relatively simple (semi-)empirical model that assumed a closed system, typical phytoplankton quotas, and minimizing or multiplicative forms of the Michaelis-Menten growth equation (Fig. $3 \mathrm{~d}-\mathrm{f})^{8}$. Both qualitative and quantitative categorization of (co-)limitation based on our experiments were also strongly related to the ratio of ambient $\mathrm{N}$ and Fe concentrations (Fig. 4a, b). Transitions between differing single/serial/co-limitation for $\mathrm{Fe}, \mathrm{N}$ and $\mathrm{Co}$ were thus reconcilable with the large-scale biogeochemical gradients observed across $1000 \mathrm{~s}$ of $\mathrm{km}$ of the surface ocean.

Our observations of widespread nutrient co-limitation suggest an interaction between the biogeochemical setting and the extant phytoplankton community. Simultaneous biological depletion of multiple nutrients provides a setting for co-limitation, and potentially drives a subsequent reinforcing biological response. All co-limited sites we identified were host to a diverse phytoplankton assemblage of both prokaryotes and eukaryotes (Fig. 2 and Extended Data Fig. 8), and although more oligotrophic, generally had higher diversity than sites under single $\mathrm{N}$ limitation (Fig. 1 and Extended Data Fig. 9). Enhanced diversity under resource co-limitation is predicted on the basis of increased niche dimensionality ${ }^{11}$ and has been observed in both terrestrial and lake systems ${ }^{19,20}$. Diverse communities are expected to tend towards community-level co-limitation because of differences across, and plasticity within, taxa for their stoichiometric requirement for the shared limiting nutrients ${ }^{11-13}$. Reciprocally, environments where multiple nutrients are simultaneously low favour diversity by encouraging a spectrum of mechanisms for accessing each fraction of total nutrient pools ${ }^{11}$. For example, following near-complete exhaustion of inorganic $\mathrm{N}$ and the most accessible dissolved Fe species, specialist acquisition strategies allow 
progressive use of different chemical forms of these nutrients, including organically bound pools or other physicochemical species. Thus alongside physical forcing ${ }^{21}$ and top-down ecological control, gradients in heterogeneous nutrient pools at biogeochemical transitions ${ }^{4}$ implicitly favour diversity and community nutrient colimitation $^{12,13}$. Consistent with this hypothesis, experimental amendment with $\mathrm{N}+\mathrm{Fe}$, and more so $\mathrm{N}+\mathrm{Fe}+\mathrm{Co}$ (or vitamin $\mathrm{B}_{12}$ ) significantly reduced diversity at the N-Fe colimited sites (Fig. 2a and Extended Data Fig. 9) presumably through reducing niche dimensions to those favouring diatoms (Fig. 2c and Extended Data Fig. 8) ${ }^{22}$.

Addition of multiple nutrients within N-limited gyre systems typically produces less dramatic chlorophyll-a increases than we observed ${ }^{15}$. Strong niche exclusion of bloom-forming diatoms, tighter grazer control, and/or lower maximal growth rates of extant populations may mute overall biomass increases to nutrient amendment within these central gyre systems. In contrast, responses to $\mathrm{N}+\mathrm{Fe}$ amendment closely resembled diatom responses to Fe-only amendment within $\mathrm{N}$ replete $\left.(>10 \mu \mathrm{mol} \mathrm{L})^{-1}\right)^{23}$ proximally Fe-limited ocean systems ${ }^{18,23}$, where addition of $\mathrm{Fe}$ fulfils nutritional requirements (i.e., Fig. 3b). Secondary chlorophyll-a biomass responses to Co amendment have also been observed in some Fe-limited regions ${ }^{1,5}$. Although likely system-dependent, our observations show that overall biomass responses can also be serially restricted by Co following addition of $\mathrm{N}+\mathrm{Fe}$ alone at the boundaries between $\mathrm{N}$ and Fe limited regions.

Like Fe, Co was relatively enriched in the ancient ocean in which algae evolved ${ }^{24}$, potentially contributing to its obligate requirement in many phytoplankton ${ }^{2}$. However, whilst the largest cellular sinks of $\mathrm{N}$ and $\mathrm{Fe}$ in phytoplankton are relatively well established $^{2}$, greater ambiguity exists for Co. Two principle functions for Co in phytoplankton have been elucidated: as a cofactor in carbonic anhydrase (CA), and vitamin $\mathrm{B}_{12}$, a cofactor in several enzymes ${ }^{2}$. Less well characterized are possible roles in phosphatases, acyltransferases and hydratases ${ }^{25}$. Assigning a Co requirement to specific biochemical roles is complicated as $\mathrm{Zn}$ or $\mathrm{Cd}$ can potentially substitute for Co-CA ${ }^{2}$, whilst many phytoplankton can grow without vitamin $\mathrm{B}_{12}$ (Ref. 26), albeit at some resource $\operatorname{cost}^{27}$. Our results support Co responses linked to both $\mathrm{B}_{12}$ and $\mathrm{B}_{12}$ independent roles (compare Experiments 5 and 10 in Fig. 1). However, statistically indistinguishable chlorophyll-a responses and similar diagnostic pigment assemblages between $\mathrm{N}+\mathrm{Fe}+\mathrm{Co}$ and $\mathrm{N}+\mathrm{Fe}+\mathrm{B}_{12}$ amendments in Experiments 7-9 support a more widespread vitamin $\mathrm{B}_{12}$ role for the added Co within the most rapidly responding taxa. This suggests tighter coupling between Co availability and vitamin $B_{12}$ production in the South Atlantic relative to previous observations in the coastal Southern Ocean where $\mathrm{B}_{12}$ additions, but not $\mathrm{Co}$, were stimulatory ${ }^{6}$. Disassembly of the supplied vitamin $B_{12}$, resulting in purposeful/inadvertent Co liberation and subsequent incorporation into $\mathrm{CA}$, cannot be ruled out. However, contrasting responses between $\mathrm{N}+\mathrm{Fe}+\mathrm{Co}$ and $\mathrm{N}+\mathrm{Fe}+$ vitamin $\mathrm{B}_{12}$ in Experiment 5 at least suggested this was not always the case, since Co additions stimulated additional growth when added in combination with $\mathrm{N}+\mathrm{Fe}$, whereas $\mathrm{B}_{12}$ did not. Thus, whilst $\mathrm{Co} /$ vitamin $\mathrm{B}_{12}$ availability clearly had a widespread impact on achievable biomass yield, resolving the biochemical function of added Co and extrapolating observations of such serial limitation to the in situ condition ${ }^{8-10}$, remains difficult at this stage (Supplementary Discussion).

Large-scale ocean circulation and biogeochemical interactions set the conditions for spatial patterns of nutrient (co-)limitation in the ocean ${ }^{1,28}$. Sub-surface ratios of two 
nutrients, such as $\mathrm{N}$ and $\mathrm{Fe}$, can thus provide a useful index for position in $\mathrm{N}-\mathrm{Fe}$ resource space $^{28}$. Deep waters feeding major upwelling zones have a high N:Fe ratio and phytoplankton growth depletes Fe before N. In contrast, surface waters in the cores of stratified gyre systems have a low $\mathrm{N}: \mathrm{Fe}$ ratio, resulting from heavily restricted $\mathrm{N}$ resupply and, presumably, input of $\mathrm{Fe}$ from aerosols. Transitions between these regimes define a shift in resource ratio space (Figs $1 \mathrm{~b}$ and $3 \mathrm{a}-\mathrm{c}$ ), and therefore potential for $\mathrm{N}-\mathrm{Fe}$ co-limitation. A previous study found overlap of $\mathrm{N}$ and $\mathrm{Fe}$ stress biomarkers within Prochlorococcus ecotypes across a transition in N:Fe ratios in the Pacific $^{4}$ and our results suggest that, at the whole-community level, diversity in phytoplankton requirements and a spectrum of acquisition strategies further broadens

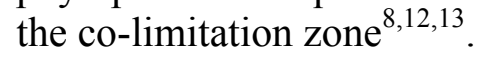

In contrast to sub-surface ratios that partly dictate relative supply ${ }^{28}$, assuming steady state, ratios of measured residual $\mathrm{N}$ and $\mathrm{Fe}$ concentrations in the surface ocean reflect the end point of biological uptake and hence the competition for these potentially limiting resources (Supplementary Discussion). The range of $\mathrm{N}: \mathrm{Fe}$ ratios measured at experimentally-determined co-limited sites thus provide an empirical means for predicting N-Fe co-limitation at large spatial scales (Fig. 4a). Surface nutrient fields from a complex global biogeochemical model ${ }^{29}$ predict only $\sim 2 \%$ of the surface ocean to fall within the stoichiometric range for $\mathrm{N}: \mathrm{Fe}$ where we found direct evidence for NFe co-limitation, with a further $12 \%$ predicted as serially limited and hence approaching co-limitation, mostly distributed in between upwelling and gyre regions (Fig. 4c). In contrast, analysis of the available surface ocean $\mathrm{N}$ and $\mathrm{Fe}$ data suggests that co-limitation may actually be $\sim 4$-fold more prevalent than these model predictions (Fig. 4c and Extended Data Fig. 10). Regions of co-limitation may thus represent a key feature of low latitude ocean that is under-represented in the global models we rely on for projecting the impact of climate change. The abrupt transitions between $\mathrm{N}$ and Fe limitation that occur within current models likely reflect the omission of sufficient diversity and physiological plasticity (e.g., related to variable nutrient demands and acquisition traits) within simulated phytoplankton communities $^{30}$.

Nutrient inputs to the ocean are projected to change ${ }^{1}$. Modified aerosol inputs, altered stratification and wind stress, and the redox status of the upwelling regimes characterizing eastern boundary currents could all directly impact nutrient fluxes and stoichiometry at gyre margins ${ }^{1}$. We find that processes of co-limitation ${ }^{8,10}$, by $\mathrm{N}$ and $\mathrm{Fe}$ as well as additional nutrients such as $\mathrm{Co}^{6,8,26}$, may be crucial in determining the responses of phytoplankton community structure and productivity to such forcing, particularly at regional scales. Accordingly, recognition of multi-nutrient serial/colimitation $^{4,8,9}$ and better representation of the underlying processes within ocean models will thus lead to more realistic projections of feedbacks regulating climate and marine food webs. 


\section{Figure legends}

Figure 1. Nutrient limitation in the SE Atlantic. a, Cruise track and locations of bioassay experiment sites. For scale, the distance between the north and south zonal transects is $\sim 3,000 \mathrm{~km}$. b, Section of interpolated $\mathrm{N}: \mathrm{Fe}$ ratios measured on the CoFeMUG cruise (orange line in a) ${ }^{14}$. Dark blue $=\mathrm{Fe}$ deficient relative to $\mathrm{N}$, white $=$ near equal deficiency, $\mathrm{red}=\mathrm{N}$ deficient. Large black and grey symbols indicate data within the range we found $\mathrm{N}$-Fe co-limitation and secondary limitation respectively. c-k, Phytoplankton responses to nutrient amendment in Experiments 210. Dots indicate replicate treatment bottles; bar heights and lines indicate the mean and range, respectively $(n=3)$. Statistically indistinguishable means are labelled with the same letter (ANOVA and Fisher PLSD $p \leq 0.05, \mathrm{n}=3$ ). Horizontal lines indicate initial values. Amendment label colour indicates $F_{\mathrm{v}} / F_{\mathrm{m}}$ was significantly increased (red) or reduced (blue) relative to the control (ANOVA and Tukey HSD $p \leq 0.05, n=3$ ). Co saturation of cation transporter sites in Experiment 8 could have induced Fe stress and the $F_{\mathrm{v}} / F_{\mathrm{m}}$ reduction ${ }^{2}$.

Figure 2. Example ecophysiological responses to nutrient amendment at a N-Fe colimited site (Experiment 8). a, Flow cytometry cell counts (relative units-mean counts, $n=3$, have been normalized to control for each cell type). $\mathrm{Nano}=$ nanophytoplankton (approximately $>2 \mu \mathrm{m}$ ); Pico=picophytoplankton (approximately $<2 \mu \mathrm{m}$ ); Syn=Synechococcus; Pro=Prochlorochoccus. The superimposed scatter plot is the Exponential Shannon Wiener diversity Index $(\text { ESWI })^{25}$, calculated using cell counts (dots and line) or pigment-derived community (crosses; see c). b, Mean fluorescence per cell (relative, as in a). c, Pigment-derived taxonomic contributions to total chlorophyll-a in ambient waters ('Initial') and after selected nutrient amendments. Percentage contributions of diatoms are labelled.

Figure 3. Factorial nutrient limitation scenarios. a-c, Initial position of seawater nutrient concentrations and movement in resource space following experimental amendments (symbols defined in Fig. 1a). Background colour represents growth rate predicted using a minimizing Michaelis-Menten equation ${ }^{8,10}$ (darker green=higher growth rate). Concentrations at nutrient limited sites generally follow a theoretical interspecific $\mathrm{N}-\mathrm{Fe}$ tradeoff curve $\mathrm{e}^{11,12}$. Dashed line indicates the theoretical transition from $\mathrm{N}$ to $\mathrm{Fe}$ limitation using assumed average phytoplankton quotas ${ }^{1}$. Solid lines define the envelope of $\mathrm{N}: \mathrm{Fe}$ ratios where we found simultaneous N-Fe co-limitation. Experiment 7 is here classified as serially $\mathrm{Fe}-\mathrm{N}$ limited, given the physiological response to Fe supply (Fig. 1h). The all-red dot represents nutrient concentrations measured at a high N, Fe-limited experimental site in the Equatorial Pacific, completing the $\mathrm{N}-\mathrm{Fe}$ limitation sequence observed in the SE Atlantic (Supplementary Table S1). d-f, Simulated nutrient utilization with phytoplankton stimulation using assumed-average phytoplankton nutrient quotas, maximum growth rates of $2.5 \mathrm{day}^{-1}$, half-saturation concentrations (for growth) set to $0.25 \mu \mathrm{mol} \mathrm{L} \mathrm{L}^{-1}$ for $\mathrm{N}$ and scaled for $\mathrm{Fe}$ and Co using average quotas, and a factor of 150 to convert phytoplankton carbon to chlorophyll-a. d-e, example simulated drawdown and chlorophyll increases compared to measured chlorophyll-a concentrations at $48 \mathrm{~h}$ (symbols representing individual bottle replicates, $n=3$, and line indicating the range). f, Predicted vs. measured growth for all experiment simulations using same parameterizations. Dotted line $=1: 1$ and solid line indicates the least squares linear regression ( $\mathrm{P}$ value for twotailed $\mathrm{F}$ test). 
Figure 4: Predicting oceanic co-limitation using $\mathrm{N}: \mathrm{Fe}$ ratios. a, discrete categorization of limitation and $\mathbf{b}$, continuous scale based on a derived '(co)limitation index' (Supplementary Discussion), as a function of observed N:Fe concentrations. Point symbols are as defined in Figures 1 and 3. Lines indicate the least squares linear regression ( $\mathrm{P}$ value for two-tailed $\mathrm{F}$ test). $\mathbf{c}$, Global co-limitation prediction using $\mathrm{N}: \mathrm{Fe}$ generated by a biogeochemical model with available observational data over plotted. Grey and yellow grid cells/observations indicate data within the serially/co-limited N:Fe range represented in $\mathbf{a}$ and $\mathbf{b}$. Thresholds where $\mathrm{N}$ and $\mathrm{Fe}$ concentrations are both characterized as replete, regardless of the $\mathrm{N}: \mathrm{Fe}$ ratio, have been applied (maximum concentrations measured under co-/serial limitation). For all panels the units of calculated N:Fe are $\mu$ mol:nmol.

All data from the current study are available from the corresponding author on reasonable request. 


\section{References}

1. Moore C. M. et al. Processes and patterns of oceanic nutrient limitation. Nat. Geosci. 6, 701-710 (2013).

2. Morel, F. M. M., Milligan A. J., \& Saito, M. A. "Marine Bioinorganic Chemistry" in The oceans and marine geochemistry, (Treatise on Geochemistry 6, 2003).

3. Behrenfeld, M. J. et al., Controls on tropical Pacific Ocean productivity revealed through nutrient stress diagnostics. Nature 442, 1025-1028 (2006).

4. Saito, M. A. et al., Multiple nutrient stresses at intersecting Pacific Ocean biomes detected by protein biomarkers. Science 345, 1173-7 (2014).

5. Saito, M. A., Rocap, G. \& Moffett J. W., Production of cobalt binding ligands in a Synechococcus feature at the Costa Rica upwelling dome. Limnol. Oceanogr. 50, 279-290 (2005).

6. Bertrand E. M. et al., Vitamin B12 and iron colimitation of phytoplankton growth in the Ross Sea. Limnol. Oceanogr. 52, 1079-1093 (2007).

7. Arrigo, K. R., Marine microorganisms and global nutrient cycles. Nature 437, 343-348 (2005).

8. Saito, M. A., Goepfert, T. J. \& Ritt, J. T. Some thoughts on the concept of colimitation: Three definitions and the importance of bioavailability. Limnol. Oceanogr. 53, 276-290 (2008).

9. Harpole W. S. et al., Nutrient co-limitation of primary producer communities. Ecol. Lett. 14, 852-862 (2011).

10. Sperfeld, E., Raubenheimer, D. \& Wacker A., Bridging factorial and gradient concepts of resource co-limitation: Towards a general framework applied to consumers. Ecol. Lett. 19, 201-215 (2016).

11. Tilman, D. Resource competition and community structure (Princeton Univ. Press, 1982).

12. Schade, J. D. et al., A conceptual framework for ecosystem stoichiometry: balancing resource supply and demand. Oikos 109, 40-51 (2005).

13. Danger, M., Daufresne, T., Lucas, F., Pissard, S. \& Lacroix, G., Does Liebig's law of the minimum scale up from species to communities? Oikos 117, 17411751 (2008).

14. Noble, A. E. et al., Basin-scale inputs of cobalt, iron, and manganese from the Benguela-Angola front to the South Atlantic Ocean. Limnol. Oceanogr. 57, 989-1010 (2012).

15. Moore, C. M. et al., Relative influence of nitrogen and phosphorus availability on phytoplankton physiology and productivity in the oligotrophic sub-tropical North Atlantic Ocean. Limnol. Oceanogr. 53, 824-834 (2008).

16. Behrenfeld, M. J. \& Milligan, A. J., Photophysiological Expressions of Iron Stress in Phytoplankton. Annu. Rev. Mar. Sci. 5, 217-46 (2013).

17. Mann, E. L. \& Chisholm, S. W. Iron limits the cell division rate of Prochlorococcus in the eastern equatorial Pacific. 45, 1067-1076 (2000).

18. Landry, M. R. et al., Biological response to iron fertilization in the eastern equatorial Pacific (IronEx II). I. Microplankton community abundances and biomass. Mar. Ecol. Prog. Ser. 201, 27-42 (2000).

19. Harpole, W. S. et al., Addition of multiple limiting resources reduces grassland diversity. Nature 537, 93-96 (2016).

20. Interlandi, S. J. \& Kilham, S. S., Limiting resources and the regulation of diversity in phytoplankton communities. Ecology 82, 1270-1282 (2001). 
21. Li, W. K. W., Macroecological patterns of phytoplankton in the northwestern North Atlantic Ocean. Nature 419, 154-157 (2002).

22. Edwards, K. F., Klausmeier, C. A. \& Litchman, E. Evidence for a three-way trade-off between nitrogen and phosphorus competitive abilities and cell size in phytoplankton. Ecology 92, 2085-2095 (2011).

23. Boyd, P. W. et al., Mesoscale iron enrichment experiments 1993-2005: synthesis and future directions. Science 315, 612-617 (2007).

24. Saito, M. A., Sigman, D. M. \& Morel, F. M. M. The bioinorganic chemistry of the ancient ocean: The co-evolution of cyanobacterial metal requirements and biogeochemical cycles at the Archean-Proterozoic boundary? Inorganica Chim. Acta. 356, 308-318 (2003).

25. Martinez, S., Yang, X., Bennett, B., Holz, R. C. A cobalt-containing eukaryotic nitrile hydratase. Biochim. Biophys. Acta - Proteins Proteomics 1865, 107-112 (2017).

26. Croft, M. T., Lawrence, A. D., Raux-Deery, E., Warren, M. J. \& Smith, A. G. Algae acquire vitamin B12 through a symbiotic relationship with bacteria. Nature 438, 90-3 (2005).

27. Bertrand E. M. et al., Methionine synthase interreplacement in diatom cultures and communities: Implications for the persistence of B12 use by eukaryotic phytoplankton. Limnol. Oceanogr. 58, 1431-1450 (2013).

28. Ward, B. A., Dutkiewicz, S., Moore, C. M. \& Follows, M. J. Iron, phosphorus, and nitrogen supply ratios define the biogeography of nitrogen fixation. Limnol. Oceanogr. 58, 2059-2075 (2013).

29. Tagliabue, A., et al., How well do global ocean biogeochemistry models simulate dissolved iron distributions? Global Biogeochem. Cycles 30, 149174 (2016).

30. Göthlich, L. \& Oschlies, A. Phytoplankton niche generation by interspecific stoichiometric variation. Global Biogeochem. Cycles 26, 1-8 (2012). 


\section{Supplementary Information}

Methods, tables, and additional discussion can be found in the Supplementary Information file.

\section{Acknowledgments}

We thank the captain, crew, and principal scientist (M. Frank) of the RV Meteor M121 cruise. We are grateful to J. Pampín Baro, J.C. Yong, and C. Schlosser for cruise support; K. Nachtigall, T. Klüver, C. Utermann, and P. Streu for technical laboratory assistance. This work was funded by a Marie Skłodowska-Curie Postdoctoral European Fellowship awarded to T.J.B (OceanLiNES; grant number 658035). Additional financial aid to T.J.B and E.A. from the European Commission is acknowledged (OCEAN-CERTAIN; grant number 603773). The cruise was funded by the DFG. Funding to T.J.B. for participation in the 2016 US GEOTRACES/OCB synthesis workshop is acknowledged.

\section{Author Contributions}

T.J.B. conceived, designed and carried out the study, analyzed the data, and wrote the first draft of the manuscript. C.M.M. and T.J.B. worked on subsequent drafts and improved the data analysis. E.P.A. co-led the research cruise and oversaw the nutrient analyses. A.E. oversaw the flow cytometry analyses. I.R. and T.J.B. analyzed the trace metal concentrations. E.M.B. contributed to interpretation of results. A.T. provided, and helped interpret, the PISCES2 model output. All authors commented on the manuscript.

\section{Author Information}

The authors declare no competing financial interests. Correspondence and requests for materials should be addressed to T.J.B. (tbrowning@geomar.de). 
Extended Data Figure 1: Phytoplankton responses to nutrient amendment at near coastal sites. a-l, Chlorophyll-a biomass, community, and $F_{\mathrm{v}} / F_{\mathrm{m}}$ changes in Experiments $1(\mathbf{a}-\mathbf{f})$ and $11(\mathbf{g}-\mathbf{l})$. Dots represent treatment replicates, bars indicate the mean, and lines represent the range. Statistically indistinguishable means are labelled with the same letter (ANOVA and Fisher PLSD $p \leq 0.05$ ). $\mathrm{N}$ was excluded from factorial due to high ambient $\mathrm{N}$ concentrations (determined on-ship).

Extended Data Figure 2: Responses of the nanophytoplankton community in the bioassay experiments. Grey data points represent cell counts in replicate treatment bottles; bar heights and lines indicate the mean and range, respectively $(n=3$; units: $\times 1000$ cells $\left.\mathrm{mL}^{-1}\right)$. Statistically indistinguishable means are labelled with the same letter (ANOVA and Fisher PLSD $p \leq 0.05, \mathrm{n}=3$; n.s. $=$ 'not significant'). Horizontal lines indicate initial cell counts. Red data points represent chlorophyll-a fluorescence per cell and blue data points represent total nanophytoplankton chlorophyll-a fluorescence, i.e. cell counts $\times$ cellular chlorophyll fluorescence (both have arbitrary units with different scales, lines indicate the range).

Extended Data Figure 3: Responses of the picophytoplankton community in the bioassay experiments. Grey data points represent cell counts in replicate treatment bottles; bar heights and lines indicate the mean and range, respectively $(n=3$; units: $\times 1000$ cells $\left.\mathrm{mL}^{-1}\right)$. Statistically indistinguishable means are labelled with the same letter (ANOVA and Fisher PLSD $p \leq 0.05, \mathrm{n}=3$; n.s. $=$ 'not significant'). Horizontal lines indicate initial cell counts. Red data points represent chlorophyll-a fluorescence per cell and blue data points represent total picophytoplankton chlorophyll-a fluorescence, i.e. cell counts $\times$ cellular chlorophyll fluorescence (both have arbitrary units with different scales, lines indicate the range).

Extended Data Figure 4: Responses of Synechococcus in the bioassay experiments. Grey data points represent cell counts in replicate treatment bottles; bar heights and lines indicate the mean and range, respectively $\left(\mathrm{n}=3\right.$; units: $\times 1000$ cells $\left.\mathrm{mL}^{-1}\right)$. Statistically indistinguishable means are labelled with the same letter (ANOVA and Fisher PLSD $p \leq 0.05, \mathrm{n}=3$ ). Horizontal lines indicate initial cell counts. Red data points represent chlorophyll-a fluorescence per cell and blue data points represent total Synechococcus chlorophyll-a fluorescence, i.e. cell counts $\times$ cellular chlorophyll fluorescence (both have arbitrary units with different scales, lines indicate the range).

Extended Data Figure 5: Responses of Prochlorochoccus in the bioassay experiments. Grey data points represent cell counts in replicate treatment bottles; bar heights and lines indicate the mean and range, respectively $(\mathrm{n}=3$; units: $\times 1000$ cells $\mathrm{mL}^{-1}$ ). Statistically indistinguishable means are labelled with the same letter (ANOVA and Fisher PLSD $p \leq 0.05, \mathrm{n}=3$ ). Horizontal lines indicate initial cell counts. Red data points represent chlorophyll-a fluorescence per cell and blue data points represent total Prochlorochoccus chlorophyll-a fluorescence, i.e. cell counts $\times$ cellular chlorophyll fluorescence (both have arbitrary units with different scales, lines indicate the range).

Extended Data Figure 6: $F_{\mathrm{v}} / F_{\mathrm{m}}$ responses to nutrient treatment. Data points represent measurements from replicate treatment bottles; bar heights and lines 
indicate the mean and range, respectively. Statistically indistinguishable means are labelled with the same letter (ANOVA and Tukey HSD $p \leq 0.05, \mathrm{n}=3$; n.s. $=$ 'not significant'). Horizontal lines indicate initial conditions. Changes in $F_{\mathrm{v}} / F_{\mathrm{m}}$ between initial $(\mathrm{t}=0 \mathrm{~h})$ and control $(\mathrm{t}=48 \mathrm{~h})$ time points likely reflect differential relaxation of PSII down regulation/PSII repair.

Extended Data Figure 7: Diel cycles in $F_{\mathrm{v}} / F_{\mathrm{m}}$ measurements in offshore waters. a-r, Diel cycles; grey dots=individual $F_{\mathrm{v}} / F_{\mathrm{m}}\left(F_{\mathrm{v}}{ }^{\prime} / F_{\mathrm{m}}{ }^{\prime}\right.$ during daytime) measurements and blue line $=100$ point moving average. Data was blank-corrected using a mean blank value for all offshore surface waters. Light blue boundaries=range generated when the blank is increased or reduced by the standard deviation of the measured blank values. Red line=photosynthetically available radiation (PAR). s, Map showing the data collection locations in relation to bioassay experiments.

Extended Data Figure 8: CHEMTAX-derived community assemblages (fractional contribution to total chlorophyll-a). $\mathbf{a}-\mathbf{h}$, Initial waters from Experiments 1-7 and 11. $\mathbf{i}-\mathbf{j}$, Initial waters and selected treatments from Experiment 9 (i) and 10 (j).

Extended Data Figure 9: Exponential Shannon Wiener diversity Indices for the experiments. Indices calculated using flow cytometry cell counts (grey dots represent treatment replicates, bars represent the mean, and lines represent the range) or pigment-derived community (black dots; $\mathrm{n}=1$ and where available). Statistically indistinguishable means for FCM-derived ESWI are labelled with the same letter (ANOVA and Fisher PLSD $p \leq 0.05, \mathrm{n}=3$ ). Horizontal lines indicate initial conditions.

Extended Data Figure 10: Potential large-scale distribution of oceanic N-Fe colimitation. a, Global surface ocean as predicted using simulated nutrient fields from an ocean biogeochemical model run (PISCES2) (Ref. 29); co-limited regions (yellow grid cells) are assigned to grid cells with an N:Fe ratio falling in the range of N-Fe colimited experiments (see Figure 4a, b); N-Fe or Fe-N serially limited regions (i.e., those approaching N-Fe co-limitation, grey grid cells) are assigned to grid cells with a $\mathrm{N}: \mathrm{Fe}$ ratio falling in the range of $\mathrm{N}-\mathrm{Fe}$ or Fe-N serially limited experiments. Large black dots show the locations where additional evidence of secondary/co-limitation between $\mathrm{N}$ and Fe has been found (see Supplementary Table S2 for details). Crosses are locations where nutrient enrichment experiments have been performed and found evidence for $\mathrm{N}$ (blue crosses) or Fe (red crosses) limitation (from synthesis by Ref. 1). b, Observational N:Fe data gridded at the same resolution as the model. Observational Fe data (Ref. 29) have been combined with interpolated World Ocean Atlas (WOA) nitrate for location and month of the dissolved Fe measurement. c, Vertical domain of $\mathrm{N}: \mathrm{Fe}$ ratios for a section of measured nutrient concentrations through the South Atlantic in austral summer (extended version of Figure 1b; CoFeMUG cruise ${ }^{14}$ ). In the central gyre, $\mathrm{N}$ supply from deeper waters is restricted by surface stratification whilst subsurface waters are Fe-deficient relative to $\mathrm{N}$, resulting from $\mathrm{N}$ remineralization and $\mathrm{Fe}$ scavenging. Large black dots indicate data points where the measured N:Fe ratio was in the range we found N-Fe co-limitation; grey dots=within bounds of measured secondary N-Fe or Fe-N limitation. For a and c thresholds where $\mathrm{N}$ and Fe concentrations are both characterized as replete, regardless of the N:Fe ratio, have been applied; these are the maximum $\mathrm{N}$ or Fe concentrations in Supplementary Table S1 where serial or co-limitation was found. 

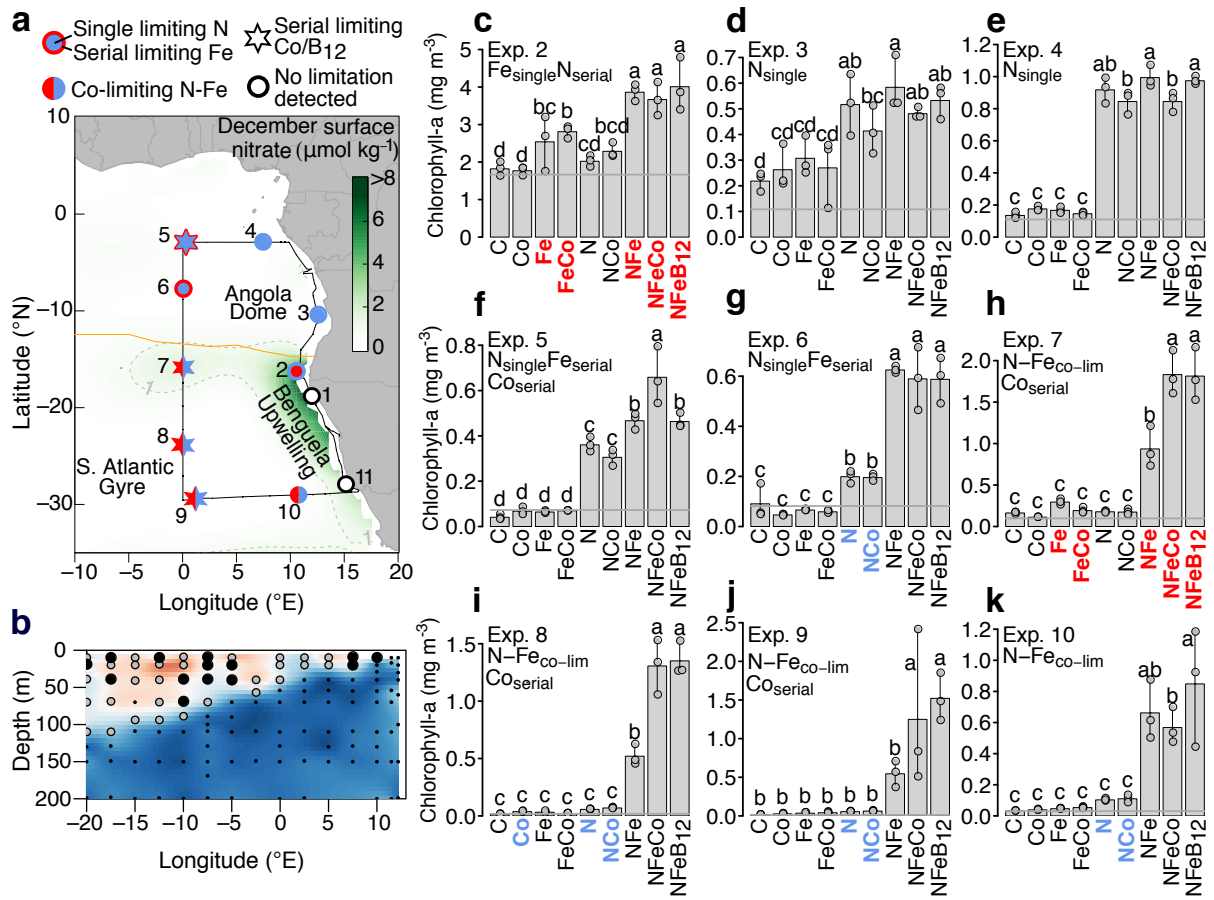

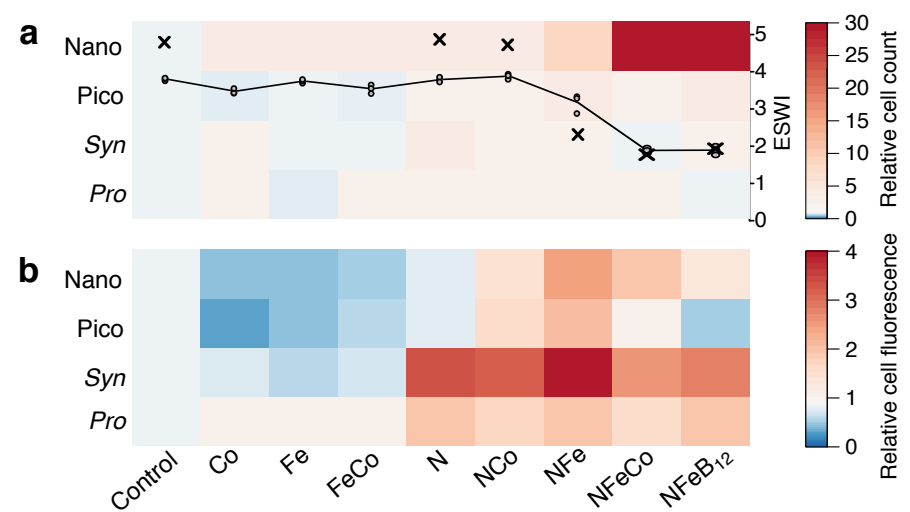

c

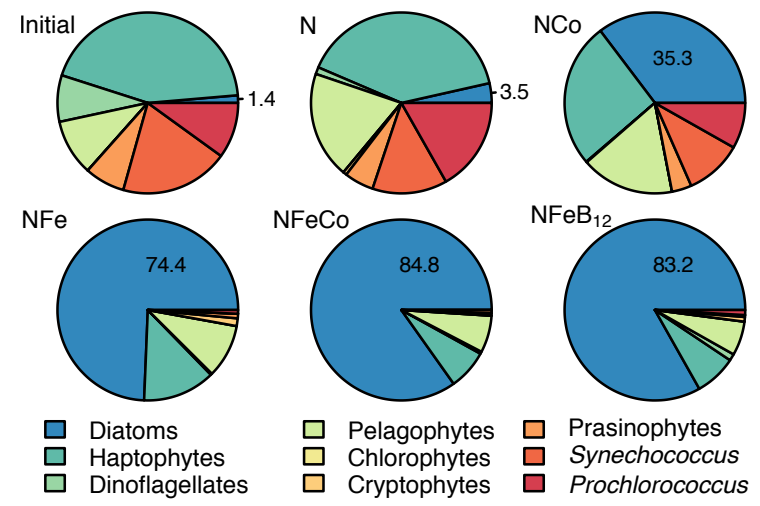



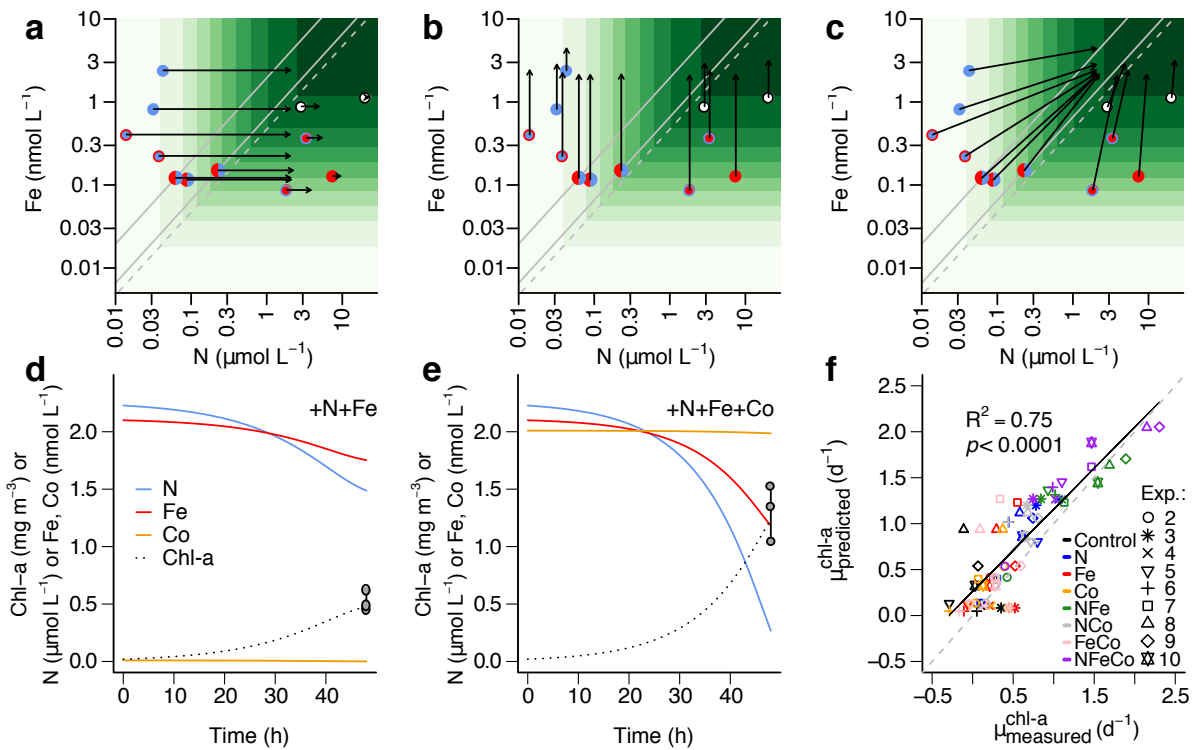

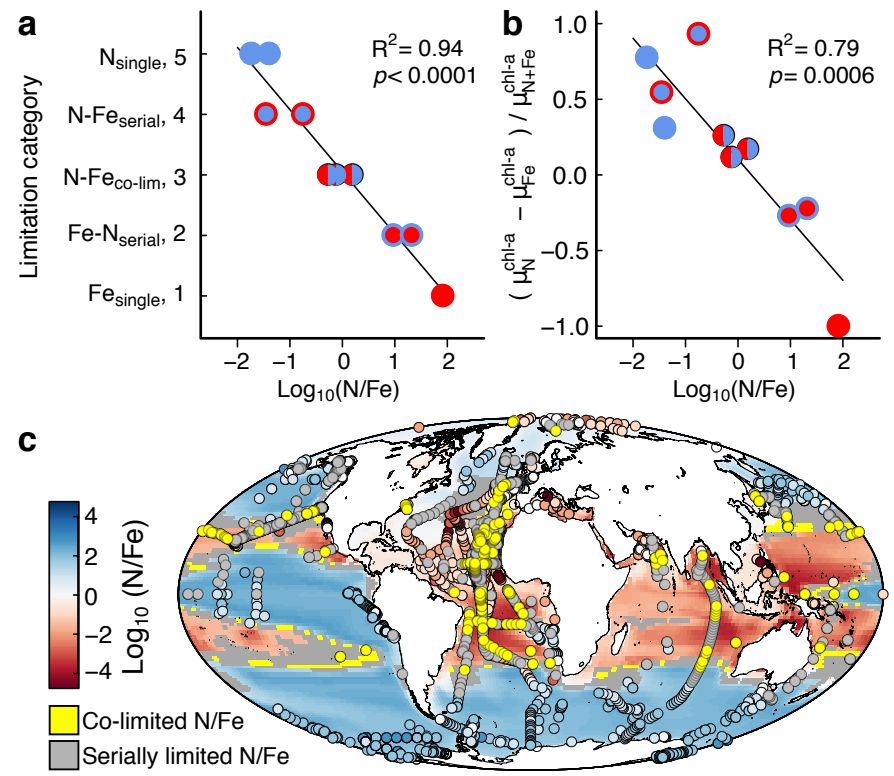